\title{
The effectiveness of implementation of mandatary institutional isolation of all mild cases by developing Fangcang hospitals against the Corona Virus Disease 2019 (COVID-19): modified SEIR model simulation
}

\section{Zhechun Zeng ( $\square$ zengzhechun@sina.com ) \\ Capital Medical University Affiliated Anzhen Hospital \\ Jinwen WANG \\ Capital Medical University Affiliated Anzhen Hospital \\ Jianglian SU \\ Capital Medical University Affiliated Anzhen Hospital \\ Huijuan ZUO \\ Capital Medical University Affiliated Anzhen Hospital \\ Jiang Xie \\ Capital Medical University Affiliated Anzhen Hospital}

\section{Research}

Keywords: COVID-19, SEIR model, isolation, Fangcang shelter hospital, Forecasting

Posted Date: July 6th, 2020

DOl: https://doi.org/10.21203/rs.3.rs-38393/v1

License: (c) (1) This work is licensed under a Creative Commons Attribution 4.0 International License. Read Full License 


\section{Abstract \\ Background}

An epidemic outbreak of a novel coronavirus (COVID-19) pneumonia has occurred in Wuhan City, China in December 2019 and subsequently led to the breakdown of the medical system. Fangcang hospital is developed to isolate patients with mild symptoms of an infectious disease from their families and communities on 28 January 2020. We present use a mathematical model to quantify the impact of the mandatory isolation strategy on the epidemic in Wuhan.

\section{Methods}

We developed a modified Susceptible-Exposed-Infectious-Removed (SEIR) model to simulate the Wuhan COVID-19 outbreak. We use reported case data up to 1 December 2019 from the Chinese Center for Disease Control and Prevention to parameterize the model. We used the model to estimate reductions in the number of confirmed cases and deaths in Wuhan.

\section{Results}

Compared with mandatory institutional isolation measures, home isolation for mild cases increase the number of confirmed cases from 51,214 to 61,349 in Wuhan, but has a more marked effect at the mortality, where death case increased by nearly $35.3 \%$ until April 25th.

\section{Conclusion}

The mandatory isolation strategy by using Fangcang hospitals applied on January 28, 2020 can effectively control the outbreak of COVID-19. We suggest that a mandatory isolation strategy be applied with success around the whole world.

\section{Contributions To The Literature}

- Isolation are public health interventions designed to protect the public by preventing exposure to people who have a contagious disease. However, the action may conflict with the interests of individual patients. The policy of mandatary institutional isolation is not widely implemented worldwide.

- We estimated to what extent this isolation measure could affect the scale of the epidemic in Wuhan, China.

- Our results will provide references for health departments in other countries to make decisions when dealing with outbreaks of COVID-19. 


\section{Introduction}

An epidemic outbreak of pneumonia unknown etiology has occurred in Wuhan City, Hubei Province of China in December 2019. The Chinese authorities identified a new type of coronavirus, which was isolated on 7 January $2020^{1}$. Coronaviruses are a large family of viruses. Some cause illness in people and others circulate among animals, including camels, cats, and bats. Animal coronaviruses are capable of evolving to infect people and subsequently spreading through human-to-human transmission. This occurred with both Middle East Respiratory Syndrome (MERS) and Severe Acute Respiratory Syndrome (SARS) $)^{2,3}$. By January 31, 2020, approximately 10000 cases had been reported in China, more than the number of confirmed cases of SARS during its 2003 outbreak. February 11, 2020, the World Health Organization (WHO) says the official name for the disease caused by the new coronavirus is Covid-19. On January 30,2020 , WHO has declared the virus outbreak a public health emergency of international concern (PHEIC) ${ }^{4}$.

The Chinese government has taken comprehensive and strict public health measures against the epidemic to reduce the speed with which cases are occurring to delay and to reduce the peak of virus activity in the community. Due to there being no vaccine and the fact that isolation is the only and most effective way to control and prevent the virus, the government of China took a quick decision to shut down Wuhan city ${ }^{5}$. Wuhan local government issued a notice to shut down the city's outbound channels at airports and railway stations starting on Jan. $23^{6}$. All families in China were advised to avoid public gatherings and close contact with others and just stay at home ${ }^{7}$. However, the number of cases is still increasing rapidly. As of January 20,2020, confirmed cases of COVID-19 in Wuhan accounted for more than $90 \%$ of all confirmed cases in China. Hospitals became overcrowded with just severely ill patients ${ }^{8,9}$. Meanwhile, persons under self-isolated at home could still infect family members and neighboring community members. Under such circumstances, Fangcang hospital is developed to isolate patients with mild symptoms of an infectious disease from their families and communities, while providing medical care, disease monitoring, food, shelter, and social activities. Those patients with mild symptoms of COVID-19 will be mandatorily put in institutional isolation. The first Fangcang shelter hospital was opened and used in Wuhan on 28th January 2020. Over the following weeks, Wuhan opened an additional 15 Fangcang shelter hospitals, providing a total of more than 2000 beds. By the closure of the last hospitals on March 10,2020, the temporary hospitals in Wuhan have received a total of more than 12,000 patients $^{10}$. At the same time Wuhan reported 8 new confirmed cases, dropping below 10 for the first time and a significant contrast with a month ago, when 1,104 cases were reported on Feb. 9.

However, COVID-19 pandemic spreads globally since April 2020. According to data from the WHO, COVID19 had affected more than 200 countries and regions with over 1.13 million confirmed cases by April 5 , $2020^{11}$. Many countries and regions have or will face a surge in infections, similar to what happened in Wuhan in January. These countries are experiencing shortages of beds in hospitals caring for the rapidly growing numbers of patients with Covid-19. Many confirmed cases had to be sent home for isolation and observation and could not receive timely treatment. 
China has started to support other countries, such as Iran in constructing Fangcang shelter hospitals to isolate and treat patients with mild to moderate patients ${ }^{12}$. However, the local government feels that the overall public health policy is different from that of China. The policy of mandatary institutional isolation is not widely implemented worldwide.

Policy decision for epidemic prevention and control depend on scientific research and judgment and need to rely on stable models, reasonable parameters, and accurate predictions ${ }^{13}$. Some scholars have adopted the traditional warehouse model (Susceptible-Exposed-Infectious-Recovered, SEIR) to fit the epidemic trend ${ }^{14}$. Some scholars further evaluated some health prevention and control strategies through predictive models, including nucleic acid detection screening and whether travel restriction can affect the spread of new coronavirus pneumonia ${ }^{15-17}$.

Quarantine and isolation are public health interventions designed to protect the public by preventing exposure to people who have or may have a contagious disease. However, these actions may conflict with the interests of individual patients. In this study, we aim to evaluate of implementation of mandatory institutional isolation for all mild cases by developing Fangcang hospitals on the epidemic dynamics in Wuhan, China. We aim to estimate how will the isolation measure mitigate the final size of the epidemic. We hope that our results will provide references for health departments in other countries to make decisions when dealing with outbreaks of COVID-19.

\section{Methods}

\section{Data sources and assumptions}

The actual epidemic data used in this article comes from the official website of Chinese Center for Disease Control (Http://2019ncov.chinacdc.cn/2019-nCoV/) and Prevention and Hubei Provincial Health Commission Epidemic situation notification data (Http://wjw.hubei.gov.cn/). It was reported that the first COVID-19 case identified first exhibited symptoms on 12/08/2019. We assume that the patient was infected on $12 / 1 / 2019$, one incubation period earlier than the onset date, and 12/1/2019 was set as day 0 of the simulation. The epidemic data from December 1, 2019 to April 25, 2020 were taken for research.

According to the current monitoring data and research, the epidemiological and clinic characters of Covid19 are as follows: (1) The incubation period of the disease is contagious ${ }^{18,19}$. (2) Asymptomatic infected persons are contagious, but the length of the contagion period, the strength, and pathway of transmission need to be further studied ${ }^{20}$. (3) According to "novel coronavirus Diagnosis and Treatment Plan (Trial

Seventh Edition)", infected population is divided into mild, common, heavy and critical types ${ }^{21,22}$. With the surge of infections placed huge pressure on the city's medical system, thousands of light and common patients with COVID-19 had to be sent home for isolation and observation.

On the 55th to 60th days after the first case, the government took a series of measures to prevent the spread of the epidemic. On January 23 , Wuhan City announced the "closure of the city", the contact rate 
between personnel is relatively stable. On January 28, Wuhan Fangcang hospitals were established to isolate and treat lightly infected persons. From this moment, all confirmed patients, including mild patients have truly achieved institutional isolation.

According to the official National Bureau of Statistics, the demographic data for 2018 published on the website (http://data.stats.gov.cn) set the permanent population of Hubei Province to 11 million.

\section{Modified SEIR Model}

The Susceptible-Exposed-Infectious-Removed (SEIR) model is a compartmental model for modeling how a disease spreads through a population. It's an acronym for Susceptible, Exposed, Infected, Recovered. The model assumes that all individuals in the population have the probability of being infected. When a disease is introduced to a population, the people move from one of these classes (or compartments) to the next. When they reach the R state, they're no longer able to be infected, they either survived the disease and are now immune or succumbed to the illness and are out of the population.

The modified SEIR Model in the present study is a stochastic SEIR model, it further expanded on the basis of the SEIR model to increase isolated exposed by tracking close contacts $\left(\mathrm{E}_{\mathrm{q}}\right)$, untreated asymptomatic patients $\left(I_{q}\right)$, untreated severe patients $\left(I_{s}\right)$, untreated normal patients $\left(I_{n}\right)$, untreated mild patients $\left(I_{m}\right)$, untreated asymptomatic patients $\left(\mathrm{I}_{\mathrm{a}}\right)$, quarantine or treated in any kinds of care facility $\left(\mathrm{Q}_{\text {hospital }}\right)$, quarantine or treated in community or home $\left(\mathrm{Q}_{\text {community }}\right)$. The conversion relationship of different types of population is shown in Figure 1.

The setting of parameters in the model is combined with epidemiological investigations, published literatures, official news releases, and expert opinions. The unknown parameters are estimated using the software's built-in optimizer, the loss function is set to minimize the root mean square error (RMSE), and iteratively solved by the Gradient descent algorithm.

Three scenarios were set during the simulation:

1. Scenario 1: With all mitigation measures that taken placed in Wuhan: using Fangcang hospital to treat and isolate all mild or asymptomatic patients in care facilities, building temporary designated hospital, city lockdown, social distancing, people stay at home, strong surveillance in community, people highly compliance to the prevention and control measures. Set all available parameters to simulate the epidemic trends of cumulative confirm cases, cumulative death cases and daily new cases that can fit the curves of Wuhan. This scenario will be used as a baseline compare with the other scenarios.

2. Scenario 2: What if no Fangcang shelter hospitals were used and during the epidemic period. Mild patients who were treated in Fangcang shelter hospitals in the past must be isolated at home with other mitigation measures still implemented in community.

3. Scenario 3: What if no strict management on mild patients. No Fangcang hospital, no strong surveillance in community, people have lower compliance to the prevention and control measures. 
When performing analysis of a certain research scenario, the parameters in the model will give its probability distribution or range of assumptions according to the literature. Through the Monte Carlo (MCMC) algorithm, iterate iteratively 1000 times, the ranges of simulation results are used to achieve a robust estimate of the scenario.

The model is built with Anylogic Professional version 8.5.2. Through the event trigger mechanism in the software, the model parameters are dynamically adjusted at a specific time point to simulate the implementation of specific prevention and control measures.

\section{Parameters}

The parameters for building the model are listed in Table 2 and 3. Notations in the model are listed in Table 1. The $\mathrm{R}_{0}$ value of COVID-19 has been calculated based on earlier data is reported in the range 1.43.9. The incubation period of the disease is generally 3-7 days, the shortest incubation period is one day, and the longest incubation period is 14 days.

\section{Results}

\section{Goodness of fit}

In Wuhan, the first case of COVID-19 was occurred on 1th December 2019. During the month of December, the number of daily cases reported was 0-8 and remained constant during the entire month. The major rise in the spread of disease started on 24th January 2020.

In the current analysis, we have used data from 1th December 2019 till 25th April 2020 as our training data. We trained our data with SEIR model and result of line of fitting is shown in Figure 2. The chart shows the cumulative number of new cases (panel a) and cumulative number of death (panel b) derived from SEIR and the actual reported data for Wuhan over time. From 1th December 2019 to 25th April 2020, the actual cumulative number of confirmed cases is 50,333 , in comparison, number of cases predicted by the model is 51,214 . A total of 3,869 deaths have occurred among 50,333 confirmed cases for an overall case fatality rate of $5.2 \%$. Simulation-based estimation of cumulative deaths by April 25 th, over 4,000 , be higher than official statistics $₫$ which have almost increased by one third in the last 6 days of the analysis.

Simulation runs well correlate with data. The measurements of goodness of fit were summarized in Table 4. The $\mathrm{R}^{2}$ is 0.991 and 0.899 for model for cumulative confirm cases and model for cumulative deaths separately.

2. Forecast an epidemic without Fangcang hospitals (Scenario 2)

We assume that the government did not take the measurement to isolate the mild patients using Fangcang shelter hospitals on the 60th days after the first case. In Wuhan, about 12,000 patients were admitted to the shelter hospital, accounting for one-third of the total number of cases with mild COVID19. These patients had to be sent home for isolation. Our model estimates that this situation (home 
isolation of some mild cases) results in $7.6 \%$ increase in infections and $17.6 \%$ increase in death by April 25th (Figure 3-panel a, panel b).

3. Forecast an epidemic with home isolation of every mild Covid-19 patients (Scenario 3 )

We assume another situation that the health care system of Wuhan was increasingly overwhelmed, hospitals can only accommodate patients with heavy and critical types. The authorities will consider follow the policy of home quarantining every Covid-19 positive person. All patients with mild to moderate COVID-19 would be sent home for isolation. Our model predicts that this situation (home isolation of every mild cases) results in $19.8 \%$ increase in infections and $35.3 \%$ increase in death by April 25th (Figure 3-panel c, panel d).

\section{Monte Carlo Experiments}

Figure 4 shows results of Markov chain Monte Carlo (MCMC) analysis based on Wuhan epidemic parameters. Under the strict prevention and control measures, including Fangcang shelter hospitals, the simulation suggests that the number of confirmed cases in Wuhan is between 48,000 and 80,000 . The cumulative deaths is between 4,500 and 6,900 (panel a-b). In comparison, the estimation of cumulative cases is between 52,000 and 10,4000 without Fangcang hospital (home quarantine some mild cases), and the cumulative deaths is between 4,800 and 9,600) (panel c-d).

Our MCMC analysis estimate for cumulative infected may be as low as 56,000 and as high as 184,000 if the authorities follow the policy of home quarantining every mild cases. Similarly, cumulative deaths are between 5,400 and 14,700 . We found that the cumulative number of confirmed cases and deaths fluctuated significantly. The home quarantine policy will increase cumulative number of confirmed cases from $16.7 \%$ to $130 \%$, increase the number of deaths from $20 \%$ to $113 \%$ (panel e-f).

The number of daily new confirmed cases is 2,800 following the policy of strict prevention and control measures with Fangcang hospital (panel g). The number will increase to 2,900 and 3,000 if the authorities follow the policy of home quarantining some mild cases or every mild case without Fangcang hospital. Furthermore, the large number of new cases per day will last longer in the latter two situations (panel h, panel i).

\section{Discussion}

COVID-19 had quickly spread to the majority of countries worldwide, affected more than 2 million individuals, and caused nearly 120,000 death $^{23}$. Although studies have described the epidemiological characteristics of patients with COVID-19, and several modeling studies have evaluated the effect of multiple public health interventions (including travel restriction, social distancing measures, home isolation and quarantine) on spread of the COVID-19 epidemic ${ }^{24-26}$, no study has yet evaluated the association of Fangcang shelter hospitals with outbreak control within Wuhan city. 
This model takes into account both the evolution of the epidemic situation and the multiple measures of prevention and control. The results revealed that the modified SEIR model is reliable in assessing the trend of the epidemic. In this study, the model indicates that the Fangcang shelter hospitals were effective at reducing the epidemic peak. By 10th March, 2020, the number of cases confirmed in Wuhan would increase by $5 \%$, the mortality would increase by $12 \%$ compared to the situation without Fangcang shelter hospitals. Furthermore, the modeling study shows that home isolation has a modest effect unless paired with behavioral changes that achieve a considerable reduction in the disease transmissibility.

The findings of this study may be valuable in the current efforts to combat the global pandemic of COVID-19. Many countries and regions are experiencing the shortage of hospital beds, similar to what happened in Wuhan three months ago. The Fangcang shelter hospitals in China were built by converting existing public venues, such as exhibition centers or sports stadiums, into health-care facilities, which can save construction cost and construction duration ${ }^{27,28}$. The scale of Fangcang hospital is massive. The 16 hospitals contained 13000 beds, which are enough to isolate and care for patients with mild to moderate COVID-1929. The time from onset of symptoms to admission to hospital for health care was decreased to about 3 days after the running of Fangcang hospital ${ }^{30}$. Early reporting, early isolation and early treatment are achieved in the prevention and control of the COVID-19 epidemic.

Isolation has been used to manage the outbreaks of communicable disease for hundreds years. Isolation restricts movement of infected individuals to limit exposure of uninfected individuals. Isolation may be either voluntary or mandatory. Mandatory isolation may be effective in limiting the spread of communicable diseases, but produce tension between the public goal of disease containment and the protection of individuals' autonomy. Considering the severity of the Wuhan epidemic in January, it is reasonable to adopt a forced isolation strategy, even if this strategy sacrifices personal autonomy.

The study has several limitations. First, the model does not fit the data well in the early stage of epidemic. The main reason may be the underestimation of number of cases in the early stage of the epidemic. There was insufficient nucleic acid detection in the first month of the outbreak, and large-scale testing began in early February, resulting in a concentrated increase in the number of diagnoses in early February. It is worth noting that the number of confirmed cases suddenly increased by 13,332 on February 10 , $2020^{31}$. In addition, Wuhan revised the death data on April 17, but only gave the final result, not revised the cumulative data day by day, which caused the cumulative death curve to rise stepwise which is obviously not a natural process of the disease. Therefore, a curve fitting has been used to provide a smooth curve that is relatively consistent with the disease development process as an alternative.

Considering the problem of overfitting and many stochastic factors in the real world, the model does not pursue a high degree of goodness of fit. Through the event trigger mechanism our model focus on simulate the growing pattern and scale of the outbreak and analysis the impact of the prevention and control measures on the overall epidemic trend.

\section{Conclusions}


The mandatory isolation strategy by using Fangcang hospitals applied on January 28, 2020 can effectively control the outbreak of COVID-19 in Wuhan, China. These findings may provide some theoretical support for public health policy makers in other countries and regions to accept the new isolation concept to combat the global pandemic of COVID-19.

\section{Abbreviations}

COVID-9: Corona Virus Disease 2019; WHO:World Health Organization; SEIR model:Susceptible-ExposedInfectious-Removed model; MERS:Middle East Respiratory Syndrome; SARS:Severe Acute Respiratory Syndrome; PHEIC:public health emergency of international concern.

\section{Declarations}

\section{Ethics approval and consent to participate}

This study was conducted according to the recommendations of the Declaration of Helsinki and was approved by the institutional review boards of the sixth clinical institute, Capital Medical University, Beijing, China.

\section{Consent for publication}

Not applicable.

\section{Availability of data and material}

The raw dataset analyzed in the current study are available from the corresponding author on reasonable request.

\section{Competing interests}

The authors declare that they have no competing interests.

\section{Funding}

None

\section{Authors' contributions}

ZZ and JW interpreted the findings and critical revision of the manuscript for important intellectual content. ZZ conceived the study design, analyzed the data, reviewed the manuscript and serves as guarantor for the contents of this paper. JW collected and analyzed the data and prepared the first draft 
of the manuscript. HZ, JS, and JX participated in the acquisition and interpretation of the data. All authors read and approved the final manuscript.

\section{Acknowledgements}

The authors thank for Ting H, Zhuhui C, and Jialin D (Beijing Carila Tech. Ltd) for computational and software technical support.

\section{References}

1. Li Q, Guan X, Wu P, et al. Early Transmission Dynamics in Wuhan, China, of Novel CoronavirusInfected Pneumonia. N Engl J Med. 2020;382(13):1199-207.

2. Dye C, Gay N. Epidemiology. Modeling the SARS epidemic. Science. 2003;300(5627):1884-5.

3. Kucharski AJ, Althaus CL. The role of superspreading in Middle East respiratory syndrome coronavirus (MERS-CoV) transmission. Euro Surveill. 2015;20(25):14-8.

4. Organization WH. 'Pneumonia of unknown cause - China', Emergencies preparedness, response, Disease outbreak news, World Health Organization (WHO). 2020.

5. Hellewell J, Abbott S, Gimma A, et al. Feasibility of controlling COVID-19 outbreaks by isolation of cases and contacts. Lancet Glob Health. 2020;8(4):e488-e96.

6. Chen S, Yang J, Yang W, Wang C, Barnighausen T. COVID-19 control in China during mass population movements at New Year. Lancet. 2020;395(10226):764-6.

7. Chinadaily. "Tibet activates highest-level public health alert" (Jan 30,2020$)$.. https://wwwchinadailycomcn/a/202001/29/WS5e318a36a3101282172739c1html.

8. Xinhua News. Noah's Ark. the story of Fangcang shelter hospitals (in Chinese). http://www.xinhuanet. Feb 19, 2020.

9. National Health Commission of the People's Republic of China. Updates on the epidemic (in Chinese). http://www.nhc.gov.cn/xcs/yqtb/202003/bf66696029ba420098164607240074f8.shtml. March 27, 2020.

10. Chen S, Zhang Z, Yang J, et al. Fangcang shelter hospitals: a novel concept for responding to public health emergencies. Lancet. 2020;395(10232):1305-14.

11. Xinhua news. China publishes timeline on COVID-19 information sharing, int'l cooperation. April 6,2020.. http://wwwxinhuanetcom/english/2020-04/06/c_138951662htm.

12. Global Times. Makeshift hospitals devised from military equipment to help Iran amid COVID-19 outbreak. March 12,. 2020 https://wwwglobaltimescn/content/1182425shtml.

13. Diekmann OH, J. A. P.. Mathematical Epidemiology of Infectious Diseases: Model Building, Analysis and Interpretation (Wiley, 2000).

14. Lin Q, Zhao S, Gao D, et al. A conceptual model for the coronavirus disease 2019 (COVID-19) outbreak in Wuhan, China with individual reaction and governmental action. Int J Infect Dis. 
2020;93:211-6.

15. Chinazzi M, Davis JT, Ajelli M, et al. The effect of travel restrictions on the spread of the 2019 novel coronavirus (COVID-19) outbreak. Science. 2020;368(6489):395-400.

16. Giordano G, Blanchini F, Bruno R, et al. Modelling the COVID-19 epidemic and implementation of population-wide interventions in Italy. Nat Med 2020.

17. Fang Y, Nie Y, Penny M. Transmission dynamics of the COVID-19 outbreak and effectiveness of government interventions: A data-driven analysis. J Med Virol 2020.

18. Backer JA, Klinkenberg D, Wallinga J. Incubation period of 2019 novel coronavirus (2019-nCoV) infections among travellers from Wuhan, China, 20-28 January 2020. Euro Surveill 2020; 25(5).

19. Rothe C, Schunk M, Sothmann P, et al. Transmission of 2019-nCoV Infection from an Asymptomatic Contact in Germany. N Engl J Med. 2020;382(10):970-1.

20. Chan JF, Yuan S, Kok KH, et al. A familial cluster of pneumonia associated with the 2019 novel coronavirus indicating person-to-person transmission: a study of a family cluster. Lancet. 2020;395(10223):514-23.

21. Xu K, Cai H, Shen Y, et al. [Management of corona virus disease-19 (COVID-19): the Zhejiang experience]. Zhejiang Da Xue Xue Bao Yi Xue Ban. 2020;49(1):0.

22. Huang C, Wang Y, Li X, et al. Clinical features of patients infected with 2019 novel coronavirus in Wuhan, China. Lancet. 2020;395(10223):497-506.

23. Encyclopedia B. The City of Wuhan. 2020.

https://baike.baidu.com/item/\%E6\%AD\%A6\%E6\%B1\%89/106764?fr=aladdin (accessed 2020-04-20 2020).

24. Novel Coronavirus Pneumonia Emergency Response Epidemiology T. [The epidemiological characteristics of an outbreak of 2019 novel coronavirus diseases (COVID-19) in China]. Zhonghua Liu Xing Bing Xue Za Zhi. 2020;41(2):145-51.

25. Special Expert Group for Control of the Epidemic of Novel Coronavirus Pneumonia of the Chinese Preventive Medicine A. [An update on the epidemiological characteristics of novel coronavirus pneumoniaCOVID-19]. Zhonghua Liu Xing Bing Xue Za Zhi. 2020;41(2):139-44.

26. WHO. Report of the WHO-China Joint Mission on Coronavirus Disease 2019 (COVID-19). 2020. https://www.who.int/docs/default-source/coronaviruse/who-china-joint-mission-on-covid-19-finalreport.pdf (accessed 2020-04-20 2020).

27. Li Q, Guan X, Wu P, et al. Early Transmission Dynamics in Wuhan, China, of Novel CoronavirusInfected Pneumonia. N Engl J Med. 2020. 10.1056/NEJMoa2001316.

28. Guan WJ, Ni ZY, Hu Y, et al. Clinical Characteristics of Coronavirus Disease 2019 in China. N Eng/ J Med 2020.

29. Information Office of Beijing Municipality, CDC B. The 58th Press conference on Covid-19. 2020. http://beijing.qianlong.com/2020/0322/3878524.shtml (accessed 2020/04/22 2020). 
30. Yang Z, Zeng Z, Wang K, et al. Modified SEIR and Al prediction of the epidemics trend of COVID-19 in China under public health interventions. J Thorac Dis. 2020;12(3):165-74.

31. Chen S, Zhang Z, Yang J, et al. Fangcang shelter hospitals: a novel concept for responding to public health emergencies. Lancet 2020.

32. Kenneth McIntosh MS, Hirsch BA. Coronavirus disease 2019 (COVID-19): Epidemiology, virology, clinical features, diagnosis, and prevention. 2020. https://www.uptodate.com/contents/coronavirusdisease-2019-covid-19-epidemiology-virology-clinical-features-diagnosis-and-prevention? source=Out\%20of\%20date\%20-\%20zh-Hans (accessed 2020-04-22 2020).

33. news N. Coronavirus: the first three months as it happened. 22,April, 2020. https://www.nature.com/articles/d41586-020-00154-w.

34. Hou C, Chen J, Zhou Y, et al. The effectiveness of the quarantine of Wuhan city against the Corona Virus Disease 2019 (COVID-19): well-mixed SEIR model analysis. J Med Virol 2020.

35. Chinazzi M, Davis JT, Ajelli M, et al. The effect of travel restrictions on the spread of the 2019 novel coronavirus (COVID-19) outbreak. Science 2020.

36. Anderson RM, Heesterbeek H, Klinkenberg D, Hollingsworth TD. How will country-based mitigation measures influence the course of the COVID-19 epidemic? Lancet. 2020;395(10228):931-4.

37. Xinhua News. Racing to build Fangcang shelter hospitals (in Chinese). Feb 6, 2020 http://wwwxinhuanetcom/local/2020-02/06/c_1125540266htm.

38. Lai S, Ruktanonchai NW, Zhou L, et al. Effect of non-pharmaceutical interventions to contain COVID19 in China. Nature 2020.

39. China News. All Fangcang shelter hospitals are suspended: achieving zero cross-infection and zero death; bolstering Wuhan's fight against COVID-19 (in Chinese). March 10,. 2020 http://wwwchinanewscom/gn/2020/03-10/9120429 shtm/; .

40. The National Health Commission of the People's Republic of China. Manual for working in Fangcang shelter hospitals (3rd edn; in Chinese). Feb 22,. 2020 https://mpweixinqqcom/s/va9vs4HuP8wRQM5fALQcrg.

41. The Guardian news. Huge rise in coronavirus cases casts doubt over scale of epidemic.. 13 Feb, 2020 https://wwwtheguardiancom/world/2020/feb/13/huge-rise-coronavirus-cases-raises-doubtsscale-epidemic-china.

\section{Tables}




\begin{tabular}{|ll|}
\hline \multicolumn{2}{|l|}{ Table 1. Notations in the model } \\
\hline Variable & Annotation \\
\hline$S$ & Susceptible \\
\hline$E$ & Exposed \\
\hline$D$ & Infectious \\
\hline$R$ & Death \\
\hline$E_{q}$ & Recover \\
\hline$I_{s}$ & Isolated exposed by tracking close contacts \\
\hline$I_{n}$ & Untreated severe patients \\
\hline$I_{m}$ & Untreated normal patients \\
\hline$I_{a}$ & Untreated mild patients \\
\hline$I_{q}$ & Patients Isolated by tracking close contacts \\
\hline$Q_{\text {hospital }}$ & Quarantine or treated in any kinds of care facility \\
\hline$Q_{\text {community }}$ & Quarantine or treated in community or home \\
\hline$Q_{1}$ & Patients mandiatory isolated in care facility \\
\hline$Q_{2}$ & Patients treated in designated hospital \\
\hline$Q_{3}$ & Patients treated in Fangcang shelter hospital \\
\hline & \\
\hline
\end{tabular}

Table 2. Parameter settings in the model 


\begin{tabular}{|c|c|c|c|c|}
\hline Parameter & Annotation & $\begin{array}{l}\text { Default } \\
\text { Value }\end{array}$ & $\begin{array}{l}\text { Range or } \\
\text { Distribution }\end{array}$ & Reference \\
\hline$N$ & Total Resident Population of Wuhan & 11000000 & Fixed & 32 \\
\hline$s$ & Susceptible crowd & $\mathrm{N}-1$ & Fixed & - \\
\hline$R_{0}$ & Basic reproduction number & 2.2 & $1.4 \sim 3.9$ & 33-35 \\
\hline si & Serial Interval & 7.5 & $5.3 \sim 19$ & 36 \\
\hline Ratio_ls & Ration of critical or severe cases & $4.50 \%$ & Fixed & 33,34 \\
\hline Ratio_In & $\begin{array}{l}\text { Ration of common or moderate } \\
\text { cases }\end{array}$ & $13.60 \%$ & Fixed & 33,34 \\
\hline Ratio_I $I_{m}$ & Ration of mild cases & $80.70 \%$ & Fixed & 33,34 \\
\hline Ratio_la & Ratio of asymptomatic cases & $1.20 \%$ & Fixed & 33,34 \\
\hline Incubation & Incubation period & 5.2 & $1 \sim 14$ & 37 \\
\hline Fatality & Average mortality inWuhan & 0.041 & $0.041 \sim 0.08$ & 33,34 \\
\hline Fatality_moderate & Mortality of common patients & $0.10 \%$ & & 37 \\
\hline Fatality_Severe & Mortality of severe patients & $8 \%$ & & 37 \\
\hline$c_{1}$ & $\begin{array}{l}\text { Number of susceptible individual } \\
\text { exposed to latent patients囚correlate } \\
\text { to the prevention and control policy } \\
\text { and the degree of personnel's } \\
\text { compliance with the policy }\end{array}$ & 10 & $\begin{array}{l}\text { Before 25th } \\
\text { January, } \\
\text { triangular(5, } \\
30,10) \text {, } \\
\text { After 25th } \\
\text { January, } \\
\text { triangular(1, } \\
10,3),\end{array}$ & $\begin{array}{l}\text { According } \\
\text { to } \mathrm{R} 0=2.2 \\
34\end{array}$ \\
\hline$c_{2}$ & $\begin{array}{l}\text { Number of susceptible individual } \\
\text { exposed to confirmed mild patients } \\
\text { under home isolation囚correlate to the } \\
\text { prevention and control policy and the } \\
\text { degree of personnel's compliance } \\
\text { with the policy }\end{array}$ & 2 & $\begin{array}{l}\text { triangular }(0, \\
5,2)\end{array}$ & 38 \\
\hline$P_{1}$ & $\begin{array}{l}\text { The probability of infection of } \\
\text { susceptible people after contact with } \\
\text { patients under the family or } \\
\text { aggregation transmission route, } \\
\text { correlate to the prevention and } \\
\text { control policy and the degree of } \\
\text { personnel's compliance with the } \\
\text { policy }\end{array}$ & 0.17 & $0.01 \sim 0.20$ & 35,38 \\
\hline$P_{2}$ & $\begin{array}{l}\text { The probability of infection of } \\
\text { susceptible people after contact with }\end{array}$ & 0.03 & $0.01 \sim 0.05$ & 35,38 \\
\hline
\end{tabular}




\begin{tabular}{|c|c|c|c|c|}
\hline & $\begin{array}{l}\text { patients during community } \\
\text { gathering, correlate to the prevention } \\
\text { and control policy and the degree of } \\
\text { personnel's compliance with the } \\
\text { policy }\end{array}$ & & & \\
\hline Interval_Y $Y_{1}$ & Days from onset to first medical visit & 4.6 & $4.1 \sim 5.1$ & $33,34,36$ \\
\hline OnsetToHospital & $\begin{array}{l}\text { Days from illness onset to } \\
\text { hospitalization }\end{array}$ & 9 & $1 \sim 19$ & 36 \\
\hline $\begin{array}{l}\text { Interval_Y } Y_{4} \\
\text { Interval_Y } Y_{5}\end{array}$ & $\begin{array}{l}\text { Days from first medical visit to } \\
\text { hospitalization }\end{array}$ & $\begin{array}{l}\text { Onset To } \\
\text { Interval__ }\end{array}$ & spital- & 36,39 \\
\hline $\begin{array}{l}\text { Interval_ } \sigma_{1} \\
\text { Interval_} \sigma_{2}\end{array}$ & $\begin{array}{l}\text { Days from infection to symptom } \\
\text { onset }\end{array}$ & 3 & $1 \sim 14$ & 36 \\
\hline Ratio_Y6 & $\begin{array}{l}\text { Proportion of mild cases entering } \\
\text { Fangcang hospital }\end{array}$ & $\begin{array}{l}\text { Wuhan } \\
35 \% \square \\
\text { others } 0\end{array}$ & fixed & 40 \\
\hline Ratio_Yg & $\begin{array}{l}\text { Proportion of mild or asymptomatic } \\
\text { cases under home isolation }\end{array}$ & $5 \%$ & $1 \% \sim 50 \%$ & \\
\hline \multirow[t]{2}{*}{ Interval_Y $Y_{12}$} & $\begin{array}{l}\text { Days from hospitalization to } \\
\text { rehabilitation for critically ill patients }\end{array}$ & 7 & $\begin{array}{l}\text { triangular }(7, \\
20,11)\end{array}$ & 35,37 \\
\hline & $\begin{array}{l}\text { Days from hospitalization to } \\
\text { rehabilitation for moderate patients }\end{array}$ & 11 & $\begin{array}{l}\text { triangular }(7 \\
20,11)\end{array}$ & 37 \\
\hline Interval_Y $Y_{13}$ & $\begin{array}{l}\text { Days from hospitalization to } \\
\text { rehabilitation for mild patients }\end{array}$ & 10 & $\begin{array}{l}\text { triangular }(5, \\
20,10)\end{array}$ & 33,34 \\
\hline Interval_Y 14 & $\begin{array}{l}\text { Days from treatment to recovery for } \\
\text { mild or asymptomatic cases under } \\
\text { home isolation }\end{array}$ & 10 & $\begin{array}{l}\text { triangular }(5, \\
20,10)\end{array}$ & 37,41 \\
\hline Interval_Y 11 & $\begin{array}{l}\text { Days from onset to diagnosis for } \\
\text { critically ill patients }\end{array}$ & 9 & $5 \sim 20$ & 33,34 \\
\hline Ratio_ $\lambda_{1}$ & $\begin{array}{l}\text { Percentage of patients tracked } \\
\text { during incubation period }\end{array}$ & 0.7 & $0.5 \sim 1$ & 35 \\
\hline 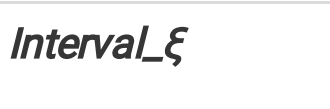 & $\begin{array}{l}\text { Time interval between recovery and } \\
\text { susceptibility again }\end{array}$ & 365 & $365 \sim 730$ & $\begin{array}{l}\text { Expert } \\
\text { opinion }\end{array}$ \\
\hline
\end{tabular}

Table 3. Formulas in the model 


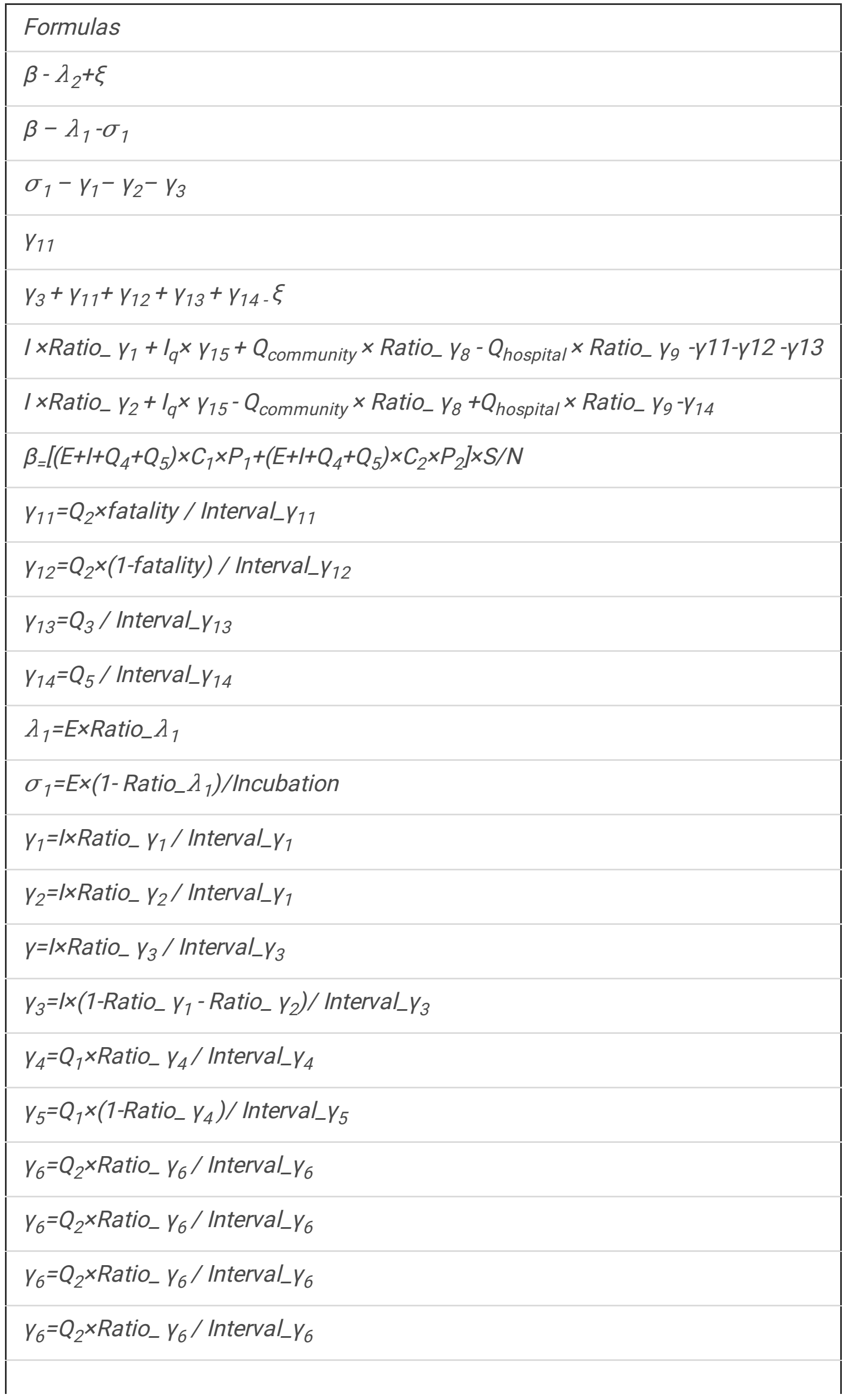


Table 4. Measurements of goodness of fit

\begin{tabular}{|lll|}
\hline & Model for Cumulative Confirm Cases & Model for Cumulative Deaths \\
\hline $\mathbf{R}^{2}$ & 0.991 & 0.899 \\
\hline MAE & 1318 & 377 \\
\hline RMSE & 2239 & 464 \\
\hline$R^{2}:$ R-Squared, coefficient of determination & \\
MAE: Mean Absolute Error & \\
RMSE: Root Mean Square Error & \\
\hline
\end{tabular}

\section{Figures}

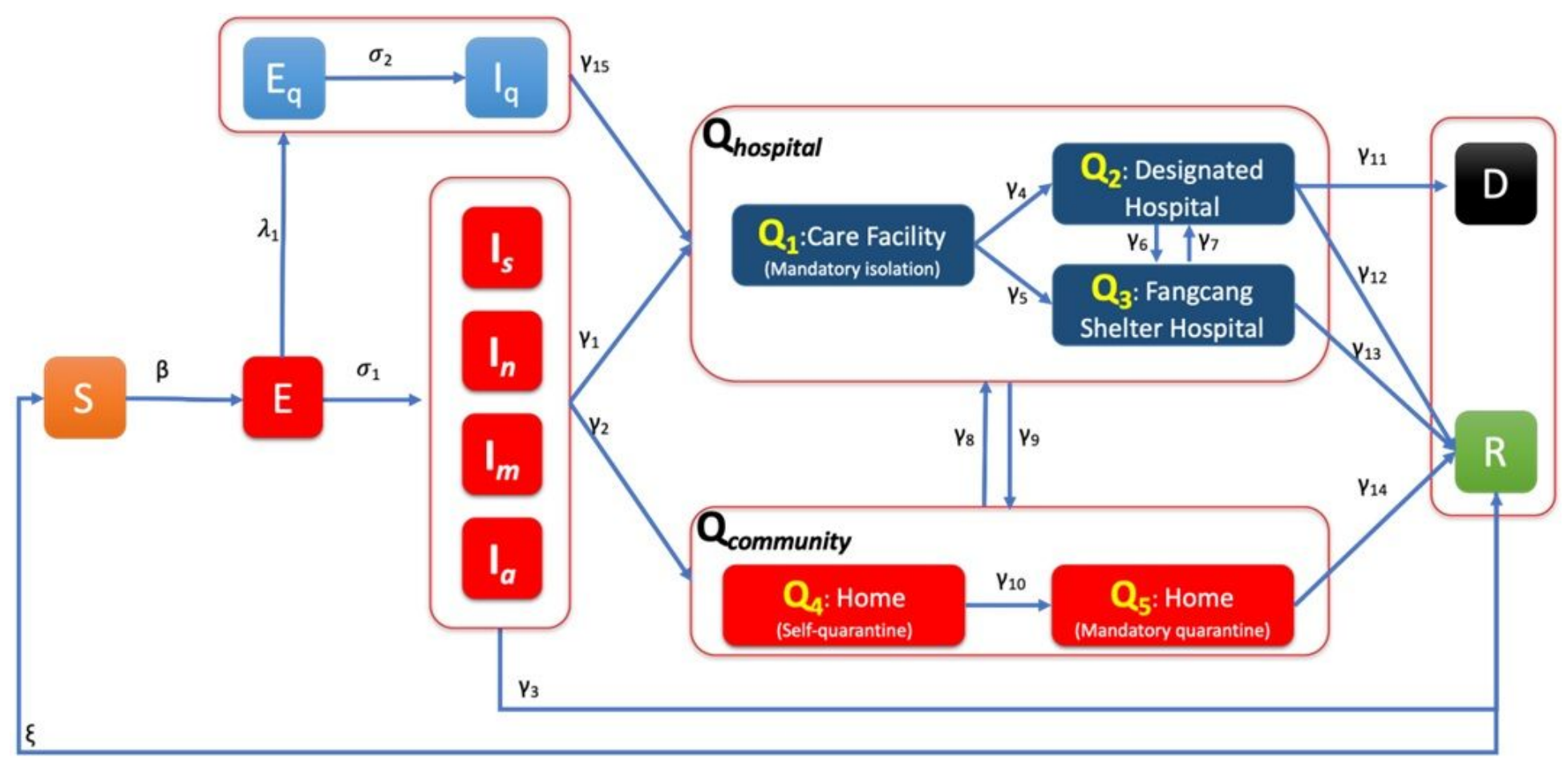

\section{Figure 1}

System Dynamic Structure of the modified SEIR model 


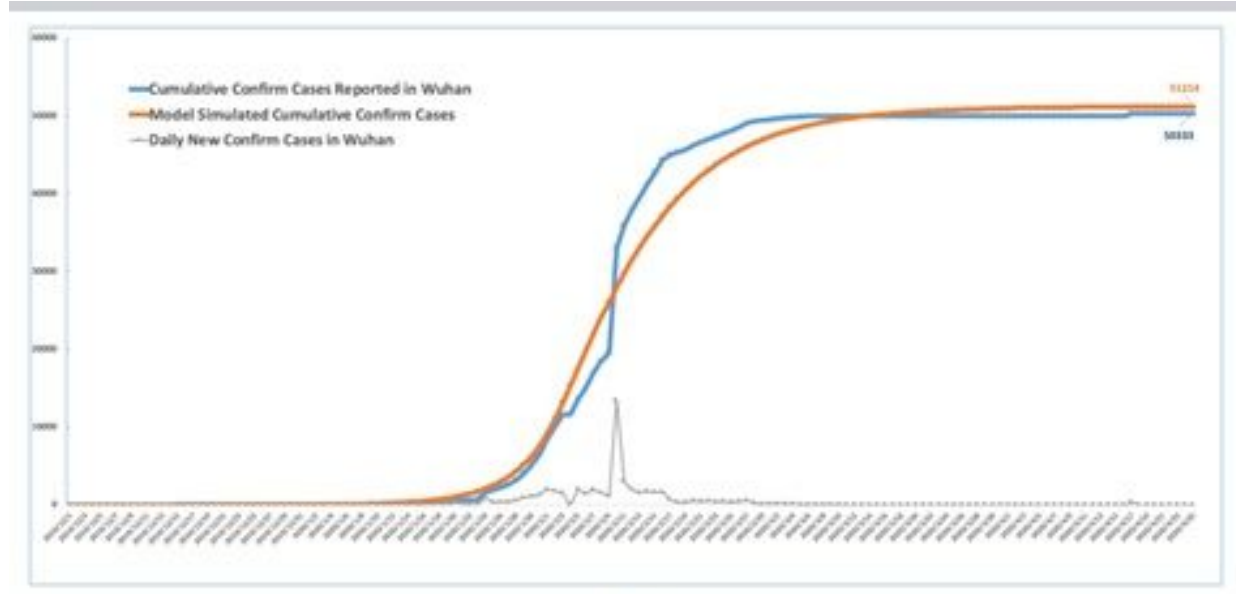

(a)

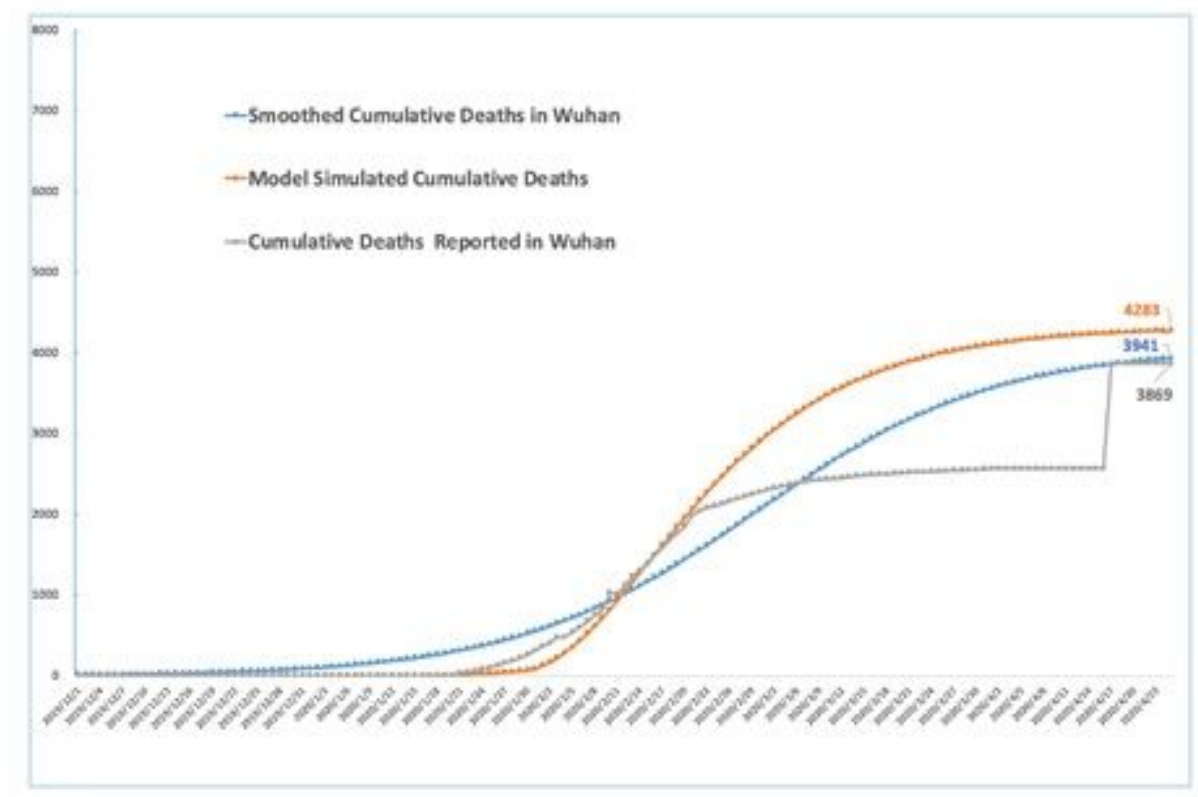

(b)

\section{Figure 2}

Comparison of the simulation predictions of reports and data: cumulative number of new cases (panel a) and cumulative number of death (panel $b$ ). 


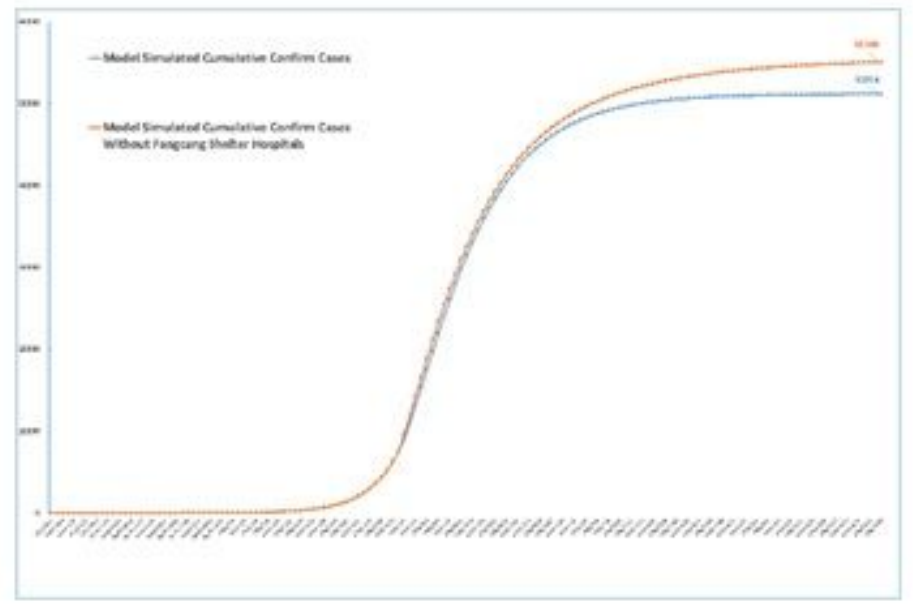

(a)

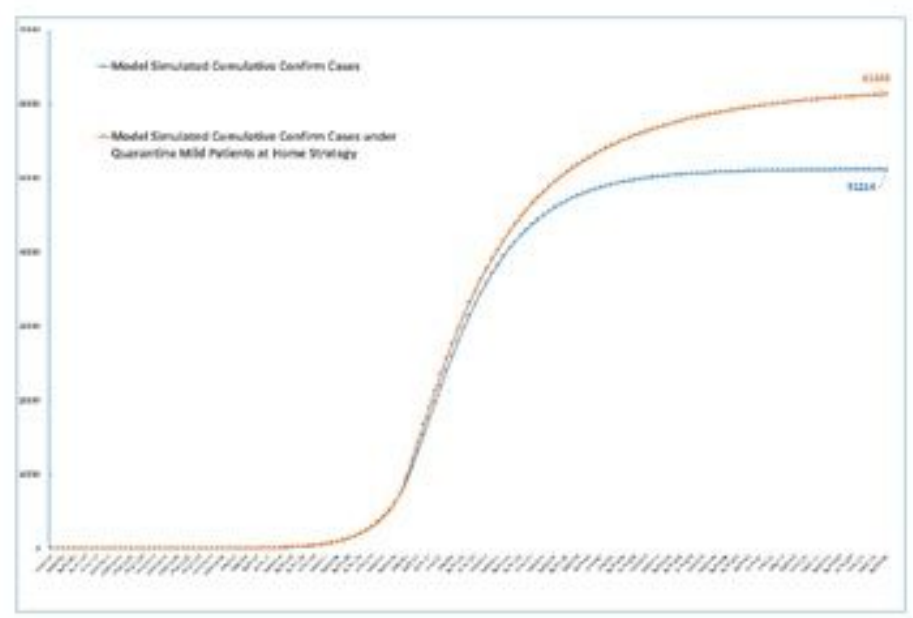

(c)

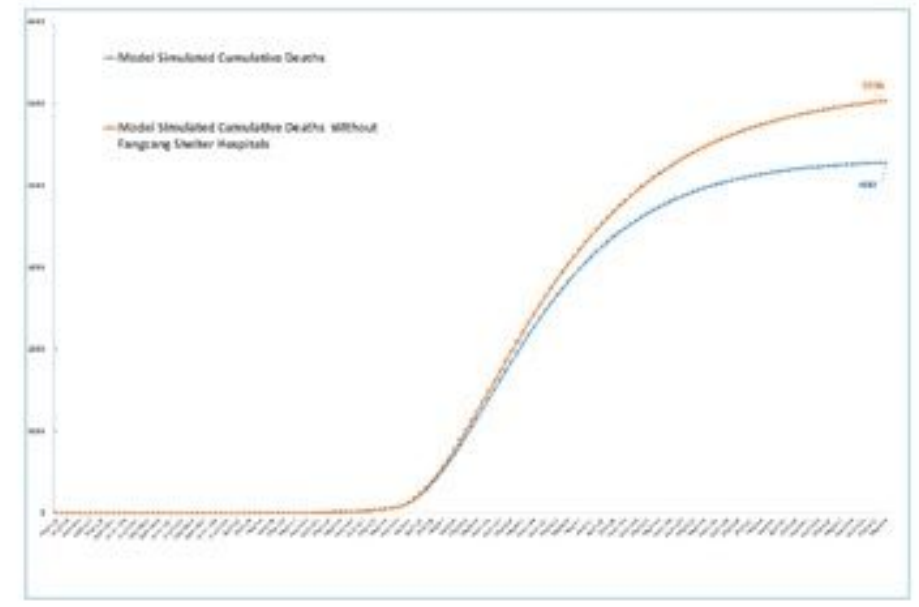

(b)

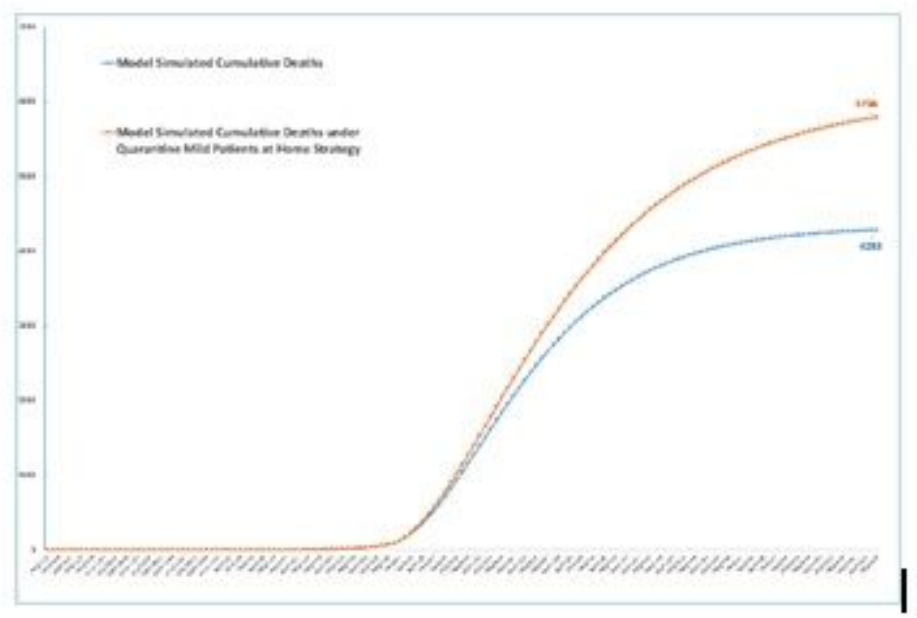

(d)

\section{Figure 3}

Comparison the number of cases or death under different measures of isolation for mild patients: simulation-based estimation of cumulative infected (Fangcang hospital quarantining mild cases vs. home quarantine some mild cases without Fangcang hospital) (a), death (b); simulation-based estimation of cumulative infected (Fangcang hospital quarantining mild cases vs. home quarantine every mild cases without Fangcang hospital) (c), death (d). 


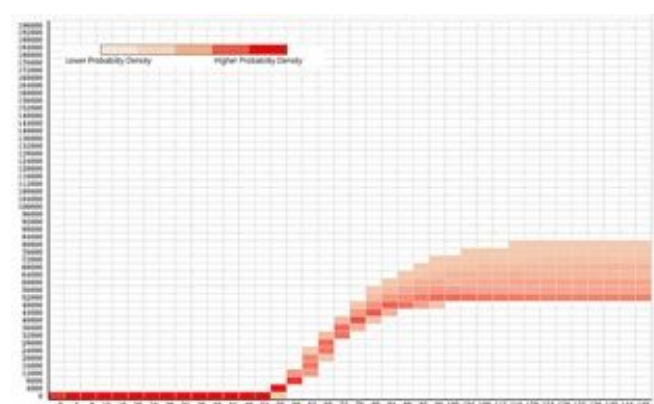

(a)

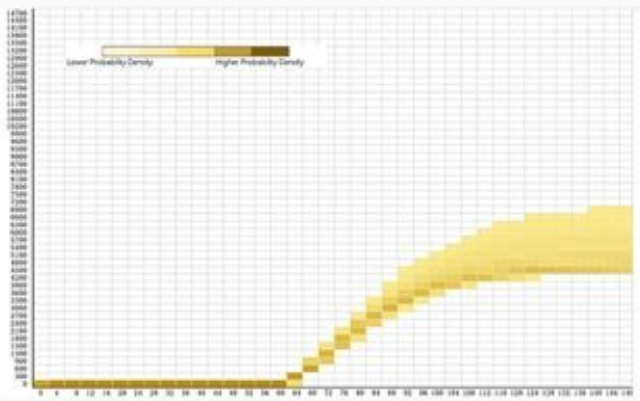

(d)

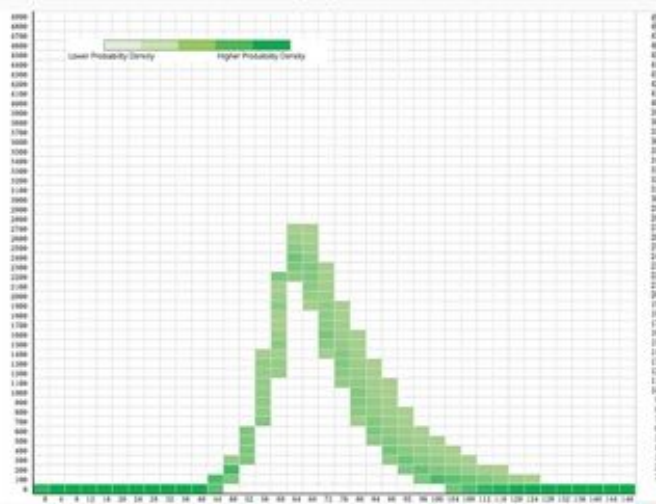

(g)

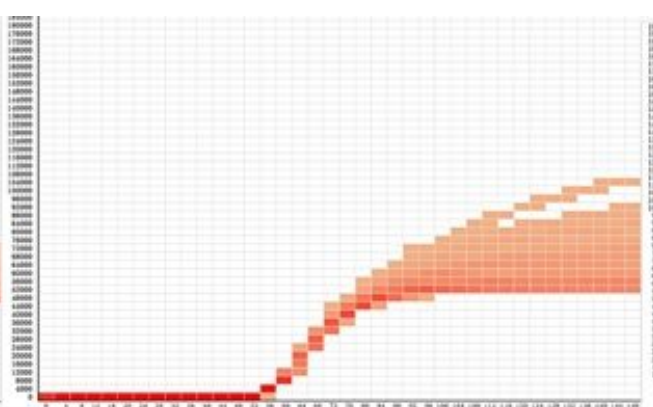

(b)

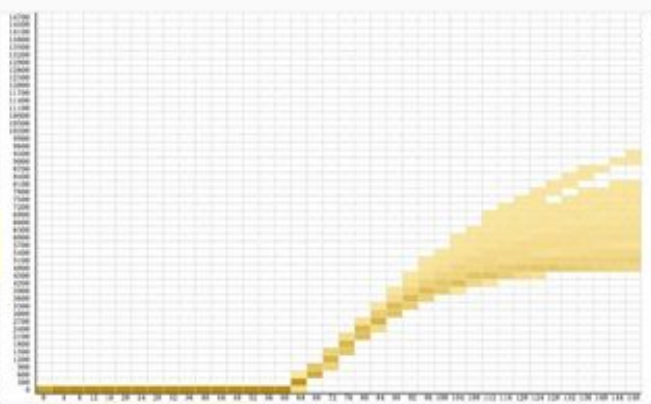

(e)

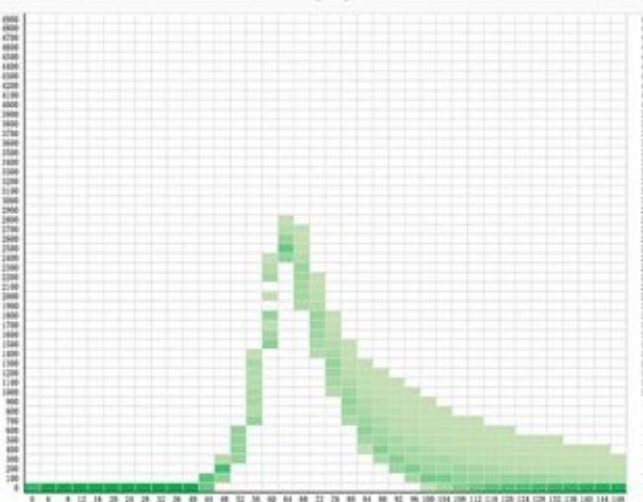

(h) (c)

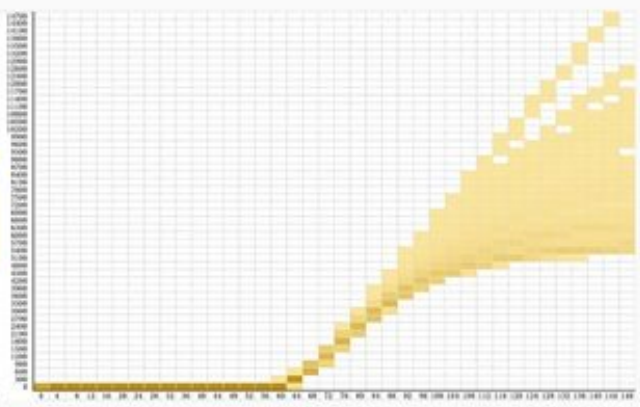

(f)

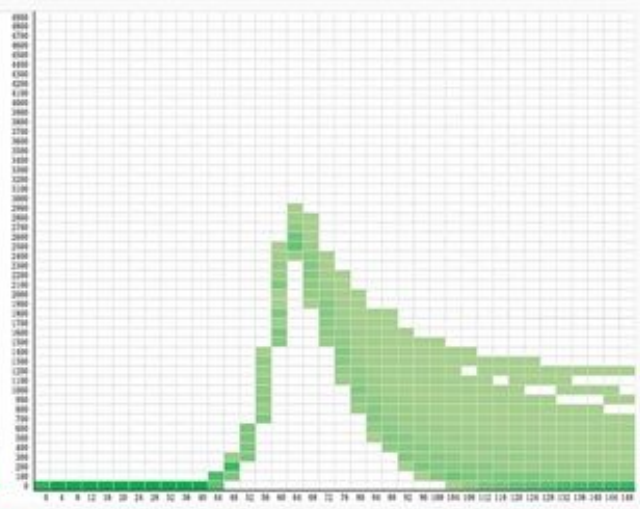

(i)

\section{Figure 4}

Markov chain Monte Carlo (MCMC) analysis under different measures of isolation for mild patients: cumulative infected (Fangcang hospital quarantining mild cases (a), home quarantine some mild cases (b), home quarantine every mild cases (c)); death (Fangcang hospital quarantining mild cases (d), home quarantine some mild cases (e), home quarantine every mild cases (f)) ; daily confirmed cases (Fangcang hospital quarantining mild cases (g), home quarantine some mild cases without Fangcang hospital(h), home quarantine every mild cases (i))

\section{Supplementary Files}

This is a list of supplementary files associated with this preprint. Click to download.

- Systemdynamicsguidelineschecklist.docx

- Systemdynamicsguidelineschecklist.docx 